\title{
Psychogenic Dystonia: a Review of 18 Cases
}

\author{
Anthony E. Lang
}

\begin{abstract}
Objective: To review the clinical characteristics and associated features found in patients with psychogenic dystonia. Methods: A 10 year retrospective chart review of all patients diagnosed by the author as having psychogenic dystonia. Results: Eighteen patients fulfilled diagnostic criteria for "Documented" or "Clinically Established" psychogenic dystonia. Clinical characteristics of the dystonia were inconsistent or incongruous with established forms of organic dystonia. Fourteen of the 18 patients had a known precipitant. In most, the onset was abrupt and progression occurred rapidly, often to fixed dystonic postures. In contrast to idiopathic dystonia, involvement of the legs was common (12 patients), despite onset in adult life. Although cases of isolated paroxysmal dystonia were excluded in the review, 10 patients had paroxysmal worsening of dystonia or other abnormal movements. Pain was a prominent feature in 14 of 16 patients with the complaint and 1 patient with documented psychogenic dystonia also had well established reflex sympathetic dystrophy (RSD). Other psychogenic movement disorders, psychogenic neurological signs and multiple somatizations were common. Long-term follow up was available for less than one-half of the patients. Outcome varied considerably; some patients had complete resolution of symptoms (including 1 who had undergone 2 previous thalamotomies) and others remained disabled by persistent dystonia. Conclusions: Dystonia is uncommonly due to primary psychological factors. At times this is an extremely difficult diagnosis to make and even when the diagnosis is confirmed, management remains very challenging. Future studies are required in hopes of providing more efficient means of distinguishing psychogenic dystonia from other dystonic syndromes especially those which rarely follow peripheral injury or accompany RSD/causalgia syndromes.
\end{abstract}

\begin{abstract}
RÉSUMÉ: Dystonie psychogène: revue de 18 cas. But: L'objectif de cette recherche est de revoir les caractéristiques cliniques et les manifestations associées chez les patients présentant une dystonie psychogène. Méthodes: Nous avons révisé rétrospectivement les dossiers de tous les patients chez qui l'auteur avait posé un diagnostic de dystonie psychogène. Résultats: Dix-huit patients remplissaient les critères diagnostiques de la dystonie psychogène "documentée" ou "cliniquement établie". Les caractéristiques cliniques de la dystonie étaient incompatibles ou sans rapport avec les formes reconnues de dystonie organique. Quatorze des 18 patients avaient un facteur précipitant connu. Chez la plupart, le début était subit et la progression rapide, souvent vers des postures dystoniques fixes. Contrairement à la dystonie idiopathique, l'atteinte des membres inférieurs était fréquente (12 patients), malgré un début de la symptomatologie à l'âge adulte. Bien que les cas de dystonie paroxystique isolée aient été exclus de l'étude, 10 patients présentaient une exacerbation paroxystique de la dystonie ou d'autres mouvements anormaux. La douleur était une manifestation importante chez 14 patients sur 16 qui se plaignaient de douleur et un patient qui avait une dystonie psychogène documentée présentait également une dystrophie sympathique réflexe bien établie (DSR). La présence d'autres désordres psychogènes du mouvement, de signes neurologiques psychogènes et de somatisations multiples était fréquente. Le suivi à long terme était disponible pour moins de la moitié des patients. L'issue variait considérablement: certains patients avaient une résolution complète des symptômes (dont l qui avait subi 2 thalamotomies antérieurement) et d'autres étaient demeurés incapacités par une dystonie persistante. Conclusions: La dystonie est rarement due à des facteurs psychologiques. Il est parfois très difficile de poser ce diagnostic et, même quand le diagnostic est confirmé, la prise en charge de ces patients est un défi. D'autres études seront nécessaires pour trouver des moyens plus efficaces de distinguer la dystonie psychogène des autres syndromes dystoniques, surtout de ceux qui suivent une lésion périphérique ou qui accompagnent les syndromes DSR/causalgie.
\end{abstract}

Can. J. Neurol. Sci. 1995; 22: 136-143

It has long been known that movement disorders can occur secondary to psychiatric disturbances. The recognition that dystonia may be a feature of primary psychopathology dates back as early as the writings of Charcot. ${ }^{1}$ Recent case series of psychogenic movement disorders include studies of psychogenic tremor, ${ }^{2}$ psychogenic dystonia, ${ }^{3}$ psychogenic myoclonus, ${ }^{4}$ and psychogenic parkinsonism..$^{5}$ Although important clinical clues
From the Department of Medicine, Division of Neurology, The Toronto Hospital, Toronto, Ontario.

RECEIVED SEPTEMBER 20, 1994. ACCEPTED IN FINAL FORM DECEMBER 16, 1994. Reprint requests to: Anthony E. Lang, M.D., The Toronto Hospital. Monton \& Gloria Shulman Movement Disorders Centre, 399 Bathurst Street, MP11-306, Toronto, Ontario. Canada MST 2S8 
exist which distinguish movement disorders as psychogenic, several important factors set psychogenic dystonia apart and it is one of the more difficult diagnoses in this group of disorders to make. Patients with idiopathic dystonia have often been misdiagnosed as having a primary psychogenic disturbance, ${ }^{6-9}$ possibly because of the bizarre nature of the movements and postures, the unusual ameliorative effects of peculiar antagonistic gestures ("sensory tricks"), the potential for isolated actions to be involved with normal performance of other activities in the same limb, ${ }^{10}$ and the occasional spontaneous remission of symptoms especially in cases of spasmodic torticollis. ${ }^{11,12}$ As early as its first descriptions, idiopathic torsion dystonia was considered a psychiatric disorder ${ }^{13}$ and this conclusion has often resulted in unnecessary suffering on the part of both the patient and family. Increasing interest in movement disorders and dystonia, along with a recognition of the problems created by the misdiagnosis of the dystonic patient led to a reluctance on the part of neurologists to consider dystonia as a symptom of primary psychopathology. Although a small number of cases had been described previously, ${ }^{14.15}$ it was the seminal report of Fahn and Williams in $1988^{3}$ that established the validity of the concept of psychogenic dystonia. These authors defined categories of degrees of certainty for the diagnosis of psychogenic dystonia and described the clinical features of 21 cases fulfilling criteria for "Documented" and "Clinically Established" psychogenic dystonia. More recently these authors have suggested combining these two groups to form a category of "Clinically Definite". ${ }^{6}$ No further series of psychogenic dystonia patients have been described since the report of Fahn and Williams. This paper reviews the author's experience with cases of clinically definite psychogenic dystonia seen over a 10 year period.

\section{Methods}

Charts of patients seen by the author at The Toronto Hospital (formerly the Toronto Western Hospital) Movement Disorders Clinic and diagnosed as having psychogenic dystonia were reviewed. Only patients fulfilling criteria for "documented" psychogenic dystonia and "clinically established" psychogenic dystonia as defined by Fahn and Williams ${ }^{3}$ were included. To be documented, the symptoms had to have been relieved by psychotherapy, suggestion or by placebo or the patient was witnessed to be free of symptoms when left alone, supposedly unobserved. To be clinically established, the dystonia was inconsistent over time or was incongruent with organic dystonia and any of the following were present: other definitely psychogenic neurologic signs, multiple somatizations and an obvious psychiatric disturbance. ${ }^{3}$ Cases of probable or possible psychogenic dystonia as defined by Fahn and Williams were excluded. For the purposes of this review, patients with exclusively paroxysmal dystonia were excluded, however, patients with continual dystonia with additional paroxysmal symptoms were included. Patients felt to have a psychogenic movement disorder superimposed on a preexisting organic movement dis$\operatorname{order}^{17}$ were also excluded.

Data obtained from this retrospective chart survey included demographics of the psychogenic dystonia population, the occurrence of precipitating factors, the nature of symptom onset, the location of onset and final distribution of dystonia, the nature and behaviour of the dystonic symptoms, the occurrence of additional paroxysmal symptomatology, the presence of other psychogenic movement disorders and other psychogenic neurological signs, the nature of the underlying psychopathology (when evident) and the presence of other contributing factors. Where available, long term follow up data were also reviewed with respect to outcome.

\section{RESULTS}

Eighteen patients, (13 females and 5 males) fulfilled the diagnostic criteria for Clinically Definite ${ }^{16}$ psychogenic dystonia; 4 were considered Documented and 14 as Clinically Established ${ }^{3}$ (Table 1). The age of onset of psychogenic dystonia was $35.5 \pm 12.7$ years (range 17-59) with males having a slightly older age of onset $(43.8 \pm 14.5$ years) than females $(32.4$ \pm 10.8 years) (NS). The duration of symptoms at the time of first assessment was $3.8 \pm 6.9$ years $(2$ months -30 years $)$. Fourteen of the 18 patients gave a history of a known precipitant to the dystonia. In 6 this was a local injury, in 5 a motor vehicle accident (usually with a whiplash-type injury) and in 1 each a febrile illness, a minor head injury and a bout of prolonged walking. Dystonia began suddenly in 9 , subacutely (over days) in 6 and the nature of symptom onset was uncertain in 3 . In most, the maximum deficit developed very early, either immediately or over days of the onset of dystonia. In 4 , the symptoms progressed over a period of weeks to 3.5 years to a generalized distribution of dystonia (i.e., involving all parts of the body). One progressed from lower limb involvement to hemidystonia (face, arm, leg) in a stepwise fashion over 5 years.

Table 1 outlines the patient details. Table 2 summarizes the distribution of dystonia at onset and at the time of clinical evaluation. At the time of first clinical assessment by the author, dystonia was present at rest in 12 patients. Seven of these had persistent unchanging rest-dystonia with no further spontaneous or induced changes in the posture. Five patients had spontaneously occurring, variable dystonia with some dystonia-free periods. Eleven patients had dystonia brought out or aggravated by voluntary activity; 1 patient had dystonia only at these times (see Table 1).

Table 3 outlines the frequency of additional clinical features. Ten patients experienced paroxysmal changes in their movement disorder superimposed upon the "continual" dystonia (see Table 1). One of these gave a history of paroxysmal episodes of increased symptoms which were no longer present at the time of clinical evaluation. Seven patients demonstrated paroxysmal worsening of dystonia. These episodes usually comprised a sudden pronounced increase in dystonia in areas involved at rest or a spread to other areas with sustained dystonic posturing typically interferring with any ongoing voluntary activity. In 4 of these patients it was possible to trigger the paroxysms on examination. In 2 this occurred while assessing extraocular eye movements (usually asking the patient to look up suddenly) (\#'s 1 \& 2 , Table 1). In another, the paroxysms were triggered by placing a tuning fork on the chest with suggestion (\#5, Table 1) and in the fourth by touching the rib cage on one side (\#11, Table 1). In this latter patient, the paroxysms and much of the continual dystonia could be suppressed by pressing on both sides of the rib cage simultaneously. Two patients had paroxysmal tremors only. 
Table 1: Patient details.

\begin{tabular}{|c|c|c|c|c|c|c|c|c|c|c|}
\hline Case \# & Sex & $\begin{array}{l}\text { Age of } \\
\text { Onset }\end{array}$ & Duration & Precipitant & $\begin{array}{c}\text { Onset/ } \\
\text { Progression }\end{array}$ & $\begin{array}{l}\text { Location } \\
\text { of onset }\end{array}$ & $\begin{array}{c}\text { Final } \\
\text { Distribution }\end{array}$ & $\begin{array}{l}\text { Nature of } \\
\text { Dystonia }\end{array}$ & Paroxysmal & $\begin{array}{l}\text { Diagnostic } \\
\text { certainty }\end{array}$ \\
\hline 1 & $\mathrm{~F}$ & 39 & $4 y$ & hand surgery & $\begin{array}{l}\text { subacute, } \\
\text { slow prog. }\end{array}$ & $\mathrm{R}$ hand & Gen & $\mathrm{R}, \mathrm{A}$ & + & $\mathrm{D}$ \\
\hline 2 & $\mathrm{~F}$ & 35 & $4 y$ & - & $\begin{array}{l}\text { uncertain } \\
\text { (?sudden), } \\
\text { slow prog. }\end{array}$ & $\mathrm{L} F \mathrm{t}$ & Gen & $\mathrm{R}, \mathrm{A}$ & + & $\mathrm{D}$ \\
\hline 3 & $\mathrm{~F}$ & 31 & $3 \mathrm{mo}$ & Minor HI & subacute & Neck & Neck, RA & $\mathrm{V}, \mathrm{A}$ & + & $\mathrm{CE}$ \\
\hline 4 & $F$ & 17 & $3 \mathrm{mo}$ & Febrile illness & sudden & Gen & Gen & $V, A$ & - & $\mathrm{CE}$ \\
\hline 5 & $\mathrm{~F}$ & 27 & $30 y$ & - & $\begin{array}{l}\text { subacute, } \\
\text { slow progr. }\end{array}$ & Legs & Gen & $\mathrm{R}, \mathrm{A}$ & + & $\mathrm{CE}$ \\
\hline 6 & $\mathrm{~F}$ & 39 & $2 y$ & $\begin{array}{c}\text { MVA } \\
\text { (pain immed) }\end{array}$ & $\begin{array}{c}\text { sudden } \\
\text { (delay “few" mo) }\end{array}$ & Legs & Legs & $\mathrm{R}$ & Tremor & D \\
\hline 7 & $\mathrm{~F}$ & 45 & $6 y$ & $\begin{array}{c}\text { MVA } \\
\text { (pain immed) }\end{array}$ & subacute & $\mathrm{L}$ hand & L hand & $\mathrm{R}$ & - & $\mathrm{CE}$ \\
\hline 8 & $\mathrm{~F}$ & 19 & $2 \mathrm{mo}$ & Walking & $\begin{array}{c}\text { sudden } \\
\text { (delay } 3 \mathrm{wk} \text { ) }\end{array}$ & $\mathrm{L} \mathrm{ft}$ & LL & $\mathrm{R}$ & $\stackrel{+}{+}$ & $\mathrm{CE}$ \\
\hline 9 & M & 25 & $9 \mathrm{mo}$ & Injury & $\begin{array}{c}\text { sudden } \\
\text { (delay } 11 / 2 \text { weeks) }\end{array}$ & RA & RA & $\mathrm{R}$ & - & $\mathrm{CE}$ \\
\hline 10 & $\mathrm{~F}$ & 28 & ly & MVA & sudden & R shoulder & Face, RA & $\mathrm{R}$ & Tremor & $\mathrm{CE}$ \\
\hline 11 & $\mathrm{~F}$ & 54 & $2.5 y$ & Fall & subacute & Toes & Gen & $\mathrm{R}, \mathrm{A}$ & + & $\mathrm{CE}$ \\
\hline 12 & $\mathrm{M}$ & 40 & $4 \mathrm{mo}$ & $(\mathrm{HIV}+\mathrm{ve})$ & sudden & Gen & Gen & $\mathrm{V}, \mathrm{A}$ & + & $\mathrm{CE}$ \\
\hline 13 & $\mathrm{~F}$ & 18 & $6 y$ & - & $\begin{array}{l}\text { uncertain } \\
\text { (? subacute) }\end{array}$ & Feet & Gen & $\mathrm{R}, \mathrm{A}$ & + & $\mathrm{CE}$ \\
\hline 14 & M & 59 & $1.8 \mathrm{y}$ & MVA & $\begin{array}{l}\text { uncertain } \\
\text { (?subacute) }\end{array}$ & Gen & Gen & $\mathrm{V}, \mathrm{A}$ & - & $\mathrm{CE}$ \\
\hline 15 & M & 37 & ly & Work injury & sudden & Neck & Neck, Hands & $\mathrm{V}, \mathrm{A}$ & - & $\mathrm{CE}$ \\
\hline 16 & $\mathrm{~F}$ & 34 & 9 mo & Fall & sudden & $\begin{array}{l}\text { Head, limbs } \\
\text { (Tremor) }\end{array}$ & Feet & A & - & $\mathrm{CE}$ \\
\hline 17 & $\mathrm{M}$ & 58 & ly & MVA & $\begin{array}{c}\text { sudden } \\
\text { (delay } 9 \text { mo) }\end{array}$ & RA & RA & $\mathrm{R}$ & - & $\mathrm{D}$ \\
\hline 18 & $\mathrm{~F}$ & 35 & $7 y$ & $\begin{array}{l}\text { fractured patella; } \\
\text { surgery } 3 \text { yr later }\end{array}$ & $\begin{array}{c}\text { subacute } \\
\text { (stepwise } \\
\text { progression) }\end{array}$ & $R L$ & Hemi & $\mathrm{R}$ & - & $\mathrm{CE}$ \\
\hline
\end{tabular}

$\mathrm{F}=$ Female

$\mathrm{M}=$ Male

$\mathrm{HI}=$ Head injury

MVA = Motor vehicle accident

Gen $=$ generalized

RA = Right arm

$\mathrm{LL}=$ Left leg

Nature of dystonia

$\mathrm{R}=$ Rest dystonia

$\mathrm{V}=$ Variable or spontaneously changing dystonia

$A=$ Action-induced dystonia

Diagnostic certainty ${ }^{3}$

$\mathrm{D}=$ Documented

$\mathrm{CE}=$ Clinically established 
Table 2: Distribution of Dystonia $(n=18)$.

Location of Onset:

$\begin{array}{ll}\text { Upper Limb } & 4 \\ \text { Neck/Shoulder } & 3 \\ \text { Lower Limb } & 7 \\ \text { Generalized } & 4\end{array}$

Final Distribution:

$\begin{array}{ll}\text { Focal }^{*} & 4 \\ \text { Segmental }^{\oplus} & 5 \\ \text { Hemi } & 1 \\ \text { Generalized } & 8\end{array}$

- left arm, right arm $\times 2$, left leg

${ }^{(1)}$ neck + arm, neck + arms, neck + face, legs $\times 2$

Table 3: Additional Clinical Features.

\begin{tabular}{|c|c|c|}
\hline Paroxysmal Component: & & 10 \\
\hline Previously (no longer) & 1 & \\
\hline Tremor only & 2 & \\
\hline Pain & & 16 \\
\hline Major Component & 14 & \\
\hline Minor Component & 2 & \\
\hline $\begin{array}{l}\text { "Trigger" } \\
\text { (eye movement exam x } 2 \text {, } \\
\text { tuning fork, touch) }\end{array}$ & & 4 \\
\hline Suppressant on examination & & 1 \\
\hline Marked Suggestibility & & 5 \\
\hline Other Psychogenic Movement Disorders: & & 10 (3 multiple) \\
\hline Tremor & 5 & \\
\hline Myoclonus & 2 & \\
\hline Other & 6 & \\
\hline
\end{tabular}

Other Psychogenic Neurological:

15

$\begin{array}{lr}\text { Give-way weakness or paralysis } & 11 \\ \text { Excessive slowness } & 5 \\ \text { Marked resistance to passive } & \\ \text { movement } & 3 \\ \text { Non-anatomic sensory changes } & 8 \\ \text { Other } & 5 \\ \text { (visual, bowel/bladder, mental state) } & \end{array}$

Multiple Somatizations:

8

Pain was a prominent symptom accompanying the dystonia in 14 of the 18 patients. Many of these patients also experienced pronounced tenderness to touch and exaggeration of pain with attempted passive manipulation of the dystonic limb or neck. One patient (\#17, Table 1) had clinical features of reflex sympathetic dystrophy (RSD) in the involved hand. Subsequent investigations, including bone scan with flow studies and placebo controlled subcutaneous phenylephrine testing confirmed the presence of RSD.

In addition to the inconsistencies of the dystonic movements and the incongruities with typical organic dystonia, by definition all patients had other features to support a diagnosis of clinically definite psychogenic dystonia ${ }^{3}$ (Table 3 ). Ten demonstrated other psychogenic movement disorders, 15 had a variety of non-organic neurological abnormalities and 8 had multiple somatizations.

Factors which may have predisposed to the development of psychogenic dystonia were not always evident. In 6 there was some form of financial gain, however, this history was not actively sought in all patients and, when present, it was not always a clear contributing factor (e.g., financial "gain" was small or the patient was less well off financially than would have been the case had they been able to continue their previous employment). Pending litigation was present in only 2 patients. Miscellaneous possible predisposing factors included chronic anxiety, longstanding depression, leaving a very dysfunctional family to live with and care for a child with cerebral palsy, a mother with possible pseudoseizures, and problems with immigration.

Previous investigations and management had varied considerably. A diagnosis of a primary psychogenic etiology had rarely been considered prior to the referral to the Movement Disorders Clinic. Thirteen patients had undergone multiple investigations which usually included at least one imaging study (CT or MRI scan), EEG, multi-modal evoked potentials, EMG and nerve conduction studies. Six patients had undergone therapeutic trials of at least 3 different pharmacological agents. Anticholinergics, benzodiazepines, baclofen, and tricyclic antidepressants were the agents used most often. One patient (\#2, Table 1) had undergone 2 separate right-sided thalamotomies. The first procedure transiently improved left-sided dystonia but the second was followed by progression of the dystonia to involve cranial musculature and the other side of the body. A second patient (\#1, Table 1) experienced the progression of symptoms from one limb to generalized involvement after reading Dr. Irving Cooper's book on movement disorders. ${ }^{18}$ She was offered stereotactic cryothalamotomy at Cooper's unit in New York but turned this down.

Sodium amytal interviews were carried out in 4 patients (1 patient before our seeing her and 3 after their Movement Disorder Clinic assessment). Dystonia did not change in 3 (\#'s 7, 10 and 17, Table 1) and in 1 (\#4, Table 1) the movement disorder symptoms increased under the influence of amytal. The patient with RSD (\#17) had an isolated reduction in the associated limb pain with amytal. Two patients received a single treatment with intravenous normal saline placebo. In 1 the dystonia completely resolved within 5 minutes of the injection (returning to the pretreatment severity 24 hours later) (\#6, Table 1). The second patient, whose dystonia had not changed in response to amytal, had an incomplete but clear response to placebo injection (\#10, Table 1). The one patient with associated RSD of the hand (\#17, Table 1) obtained a partial response of dystonia to local anaesthetic brachial plexus block. However, saline placebo block and suggestion resulted in a marked improvement in pain and particularly the dystonic posturing and immobility of the hand in the absence of features of sympathetic paralysis. 
Ten patients were seen only once in consultation. Eight patients were seen on several occasions and 5 of these were admitted to hospital for assessment and management. The patient who had previously undergone thalamotomies obtained a rapid and complete remission in her symptoms of 4 years duration shortly after admission to hospital for withdrawal of antidystonia medication and physiotherapy. The second patient described above, who had been offered thalamotomy for severe generalized dystonia, signed herself out of hospital when an amytal interview was proposed. She was seen sometime later by the author at a lay symposium on dystonia. At this time, no dystonia was evident over a prolonged period of observation, however, a formal examination was not performed. Two other patients experienced a marked improvement in the severity of their dystonia over the course of follow-up and more moderate improvement was seen in a third. Dystonia persisted in 3 patients despite hospitalization in 2 and active psychiatric intervention in all 3.

Formal psychiatric assessment was performed in only a small number of patients. As evaluated informally by the author, the primary psychiatric diagnosis (Axis I) was conversion disorder in the majority while the diagnosis of a somatization disorder possibly accounted for 3 or 4 of the patients. None could be definitely diagnosed as having a factitious disorder or malingering. Where a comorbid Axis I diagnosis was evident this was typically an affective disorder or an anxiety disorder.

\section{Discussion}

Differentiating organic neurological signs from those caused by underlying psychological factors has been a topic of clinical discussion since the early history of neurology. Gowers ${ }^{19}$ is well known for his writings in this field and the general principles he outlined apply today. These concepts were incorporated into the diagnostic criteria of Fahn and Williams ${ }^{3}$ who emphasized that an unequivocal diagnosis of psychogenic dystonia requires that there be inconsistencies in the movement disorder over time and that the abnormal movements and postures be incongruous with dystonia seen in other organic syndromes. A corollary of these points, therefore, is the fact that the neurologist making a diagnosis of psychogenic dystonia has considerable experience in the clinical evaluation of patients with organic dystonic syndromes. Fahn and Williams found that primary psychopathology is an uncommon cause of dystonia, accounting for somewhat less than $3 \%$ of all dystonia patients referred to a movement disorders centre. It represents a higher proportion of certain subgroups of dystonic patients, particularly those with adult-onset foot or leg involvement with continual dystonia or those with paroxysmal dystonia. ${ }^{3}$ Table 4 lists features which may be helpful in differentiating psychogenic dystonia from idiopathic torsion dystonia.

The inconsistencies of the movement disorder may be quite varied. The patient may be witnessed free of dystonia on surreptitious observation. In the current era of litigation, this documentation is sometimes provided through videotapes obtained by private detectives hired to observe the "plaintiff" by defence or compensation-board lawyers. The dystonia may subside upon distraction or is precipitated by suggestion or attention drawn to a particular part of the body. A common observation in the present group of patients was the inability to move or perform with
Table 4: Features Which Help Distinguish Psychogenic Dysıonia from Idiopathic Torsion Dystonia.

\begin{tabular}{ll}
\hline Psychogenic Dystonia & Idiopathic Torsion Dystonia \\
Onset with resting dystonia & Onset with action dystonia \\
Adult-onset leg involvement common & Leg involvement rare with adult-onset \\
Often fixed spasm & Mobile spasms
\end{tabular}

Rapid progression and spread to maximum disability early in the course

Dystonic movements inconsistent over time

Slow progression

Consistent over time (caution: rarely patients with cervical dystonia may change the direction of dystonia after a remission)

No geste antagoniste

Geste frequent

Selective disabilities or abilities inconsistent with fixed spasms

Painful (often with pronounced tendemess to touch and exaggeration with passive movement)

No improvement after sleep

Surprising abilities despite severe movements and postures (caution: action dystonia may result in selective disabilities; some patients with "paradoxical dystonia" improve with action)

Usually painless (caution: patients with cervical dystonia often have pain)

Symptoms often improve briefly after sleep

Attempted voluntary movement to command in the opposite direction of the dystonic posturing may activate antagonists with little apparent action in agonist muscles (limb or digit may do the opposite of what is requested by the examiner)

Paroxysmal dystonia (isolated or mixed with persistent dystonia) and/or other paroxysmal movements

Other psychogenic movement disorders

Voluntary movement and attempts to overcome the dystonia often results in further cocontraction of agonists and antagonists with variable changes in the dystonic posturing

Paroxysms not a feature (caution: exclude other causes of paroxysmal dystonia/dyskinesias)

Other movements possible (especially tremor, myoclonus)

Other nonorganic neurological features (see Table 3 and ${ }^{3}$ )

(Caution: Important to consider a psychogenic movement disorder or other psychogenic features superimposed on an organic movement disorder ${ }^{17}$ )

Precipitant common

Precipitant uncommon

Remissions: spontaneous or with nonphysiological treatments

(Caution: spontaneous remissions occasionally occur, especially in cervical dystonia)

No family history Family history not uncommon

the affected limb on command in the face of witnessed ability to do so at other times. The dystonia may result in selective disabilities and certain abilities may be inconsistent with the nature of the dystonia such that the patient is able to perform certain tasks (for example toiletting or attending to other hygienic tasks) which should have been impossible given the nature of the persistent dystonic posturing found on examination. However, one 
has to exercise extreme caution in ascribing these "inconsistencies" to a psychogenic problem given the fact that organic idiopathic dystonia may only be present with action (i.e., not evident at rest) and may affect only selected activities and not others. It is also quite impressive how patients disabled and disfigured by organic dystonia can successfully accomplish seemingly impossible tasks. ${ }^{20}$

The incongruities with classical dystonia are particularly important in the diagnosis of these cases. Like Fahn and Williams ${ }^{3}$ we found a high incidence of adult-onset leg involvement (12 of 18), a feature most atypical of idiopathic torsion dystonia. ${ }^{10}$ Although organic dystonia presents a wide array of bizarre movements and postures, these tend to be rather stereotypic in their clinical behaviour in an individual patient. Patients with psychogenic dystonia often differ in this regard. Individual "dystonic" spasms often demonstrated considerable variability in the direction or nature of the posturing. Although patients with isolated paroxysmal dystonia were excluded from this review, the majority of our patients experienced additional paroxysmal changes in their dystonia or other superimposed paroxysmal dyskinesias. Fahn and Williams found that a third of their total psychogenic dystonia population had isolated paroxysmal dystonia and one-quarter of all of their cases of paroxysmal dystonia were considered to have a primary psychogenic cause. ${ }^{3}$ When paroxysms were a feature of the disorder in our patients, it was sometimes possible at the time of examination to induce them as well as to suppress them. Patients often demonstrated a considerable degree of suggestibility with respect to the presence of these paroxysmal features. In addition to dystonic postures, the patients often demonstrated elaborate, bizarre or complex abnormal movements which sometimes defied classification into the usual dyskinesia subgroups. ${ }^{21}$ Patients also commonly demonstrated extreme slowness of voluntary movement and the performance of various tasks (e.g., finger to nose testing) was often incomplete or inaccurate. The tendency to get "hung up" in the last few centimetres of the attempted movement was common. Many patients had marked resistance to passive movement that gave the impression of active or voluntary muscle contraction. These patients were often unable to activate the same muscles on command but commonly contracted the antagonists instead. In organic dystonic syndromes the tone may vary considerably. At times resistance to passive movement is pronounced (sometimes termed "dystonic rigidity") but this is clearly distinct from the resistance appreciated in the psychogenic dystonia patients described here.

The severity of dystonia does not assist in distinguishing between organic and psychogenic dystonia. The dystonic spasms which occurred in these patients were sometimes quite extreme and disfiguring, resembling the severe contortions which can be seen in organic dystonic syndromes. In 2 patients these were so severe as to encourage neurosurgeons with considerable experience in the functional neurosurgery of movement disorders to offer stereotactic thalamotomy. Neither does a long duration of symptoms separate organic from psychogenic dystonia. In these patients, the dystonia had been present for an average of almost 4 years at the time of first evaluation by the author and in 1 case the symptoms had been present for 30 years.

The high frequency of a precipitating event and the nature of the clinical course both merit comment. A small proportion of patients with classical idiopathic dystonia provide a history of injury or some other similar precipitating factor. However, the role of this event in causing the dystonia remains uncertain. In a recent case-control study involving 71 patients with idiopathic torsion dystonia, Fletcher et al. ${ }^{22}$ found no association between injury and dystonia. On the other hand, dystonia following peripheral injury has been described in several reports. ${ }^{23-28}$ The extent to which psychological factors have played a role in these cases is not clear. The clinical nature of this "dystonia" is usually quite distinct from that of idiopathic dystonia. Here, the abnormal postures are typically fixed and not specifically induced by action. Another common feature in these patients, as seen in many of our cases, as well as those of Fahn and Williams, ${ }^{3}$ has been the rapid onset and progression to a state of fixed postural deformity commonly followed by a static course. This is not at all characteristic of idiopathic torsion dystonia or of most other secondary dystonias ${ }^{29}$ with the possible exception of a unique autosomal dominant form of rapid onset dystonia and parkinsonism described recently. ${ }^{30}$ Schwartzman and Kerrigan described features of "dystonia" in all of their 43 patients with reflex sympathetic dystrophy (RSD) complicated by a movement disorder. ${ }^{26}$ Bhatia et al. ${ }^{27}$ described 18 patients with the "causalgia-dystonia syndrome". As in many of our patients, the dystonia in these cases was precipitated by peripheral injury which was often seemingly inconsequential. Dystonia typically developed acutely, usually with a fixed dystonic posture. In some of these cases the dystonia spread to uninjured limbs, often quite rapidly. These features, as well as additional clinical aspects suggesting behaviour incongruous with organic dystonia, encouraged us to propose that at least some of the patients described could have had psychogenic dystonia. ${ }^{31}$ Although Schwartzman and Kerrigan disagreed with this suggestion, ${ }^{32}$ Bhatia and his colleagues acknowledged this as an important potential explanation for the dystonia in some of their cases. ${ }^{27}$ They emphasized the overwhelming preponderance of young women in their series as well as in previous studies, ${ }^{23}, 26$ a feature which was also seen in the present survey.

As in the reports of Schwartzman and Kerrigan ${ }^{26}$ and Bhatia et al., ${ }^{27}$ limb, neck or shoulder pain was a common and often major complaint accompanying the dystonia in our patients. Patients with other forms of dystonia may experience discomfort in the involved muscles and some, particularly those with spasmodic torticollis, may have pain as a principal complaint. However, the frequency and severity of the pain in our patient population was striking and atypical for most forms of organic dystonia even those with extreme distorted posturing. In addition to the pain, patients commonly experienced pronounced superficial tenderness and exaggeration of pain on passive movement. No attempt was made to retrospectively determine how many patients could have been classified as having causalgia. However, one patient did have well documented RSD. Local anethestic block of the brachial plexus improved pain and dystonia; however, placebo block resulted in a much more impressive response. Considerable caution must, therefore, be used in ascribing all of the movement disorders which accompany $\mathrm{RSD}^{26}$ to an "organic" source. On the other hand, additional patients were seen over the same ten year period who had developed painful dystonia, with or without RSD, following peripheral injury but who lacked any evidence to support a psychogenic cause. Further research will be required to define more reliable methods of distinguishing organic from psychogenic 
dystonia in this difficult population. For example, it would be interesting to assess reciprocal inhibition in these patients in view of the abnormalities documented in idiopathic and symptomatic limb dystonia. ${ }^{33.34}$ However, before such studies could be used to differentiate organic from psychogenic dystonia, they would have to be performed in a number of patients subsequently proven to be psychogenic since it is not known whether the electrophysiological abnormalities described are a cause of the dystonia or a result of longstanding "dystonic" posturing. Until reliable differentiating tests become available, extreme caution must be exercised in providing a definitive diagnosis. An unequivocal and pronounced response to placebo can be extremely helpful in establishing a diagnosis. However, some benefit is possible in organic dystonia, and a response may be impossible in cases of psychogenic dystonia where contractures have developed. Our experience suggests that amytal interviews may be of little diagnostic value, although they may provide useful insight into the underlying psychopathology in cases where the diagnosis has been established by other means. When diagnostic uncertainty persists it is best to give the patient the "benefit of the doubt" and continue careful follow up. Unfortunately, treating these patients as an organic disorder will not necessarily improve the prognosis. In the causalgia-dystonia patients studied by Bhatia et al., ${ }^{27}$ all methods of conventional treatment failed to relieve either the pain or the dystonia. In 16 the symptoms persisted and in 2 they subsided spontaneously.

This retrospective chart review has two major shortcomings: the lack of psychiatric documentation and the limited follow-up in most cases. These factors, in part, relate to the regional nature of our referral practise and the long distances that many patients had to travel in order to be seen. In the early years of this experience, the importance of long-term, ongoing psychiatric involvement became evident and with this understanding a concerted effort was made to initiate the necessary psychiatric care locally, rather than admit the patient to our institution and then attempt to transfer the critical ongoing care at a later date.

The informal psychiatric assessment of our patients concurs with the larger and better documented experience of Williams, Ford and Fahn. ${ }^{16}$ These authors recently reviewed the psychiatric aspects of 24 patients with clinically definite psychogenic movement disorders ( 7 with dystonia as one component) hospitalized for formal psychiatric evaluation. Eighteen of 24 (75\%) carried a primary psychiatric diagnosis (Axis l) of a conversion disorder, while $3(12.5 \%)$ had a somatization disorder, $2(8.3 \%)$ a factitious disorder and 1 had malingering. All patients had at least one comorbid Axis I diagnosis, typically an affective disorder $(71 \%)$ or an anxiety disorder $(17 \%)$. Axis $\mathrm{II}$, delineating developmental or personality disorders, applied to $67 \%$ of their cases.

Long-term follow up was available in only 8 of our 18 cases. In those seen over variable periods of follow up, prognosis ranged from complete resolution of dystonia to persistence despite active psychiatric intervention. Fahn and Williams have outlined a detailed course of management for psychogenic dystonia ${ }^{3}$ which was also pursued in a proportion of our cases. This often requires prolonged hospitalization and the involvement of a neurologist, a psychiatrist and physiotherapists, nurses and other health professionals dedicated to the management of these cases. Further studies will be required in order to determine the short-and long-term effectiveness of this approach and whether there are any features which might predict the likelihood of success. Our failure to obtain benefit in some patients emphasizes the need for caution in providing a prognosis. Recalcitrant cases may be left with longstanding severe disability including permanent contractures resulting from persistent abnormal posturing. ${ }^{3}$

\section{REFERENCES}

1. Charcot JM. Hysterical contractures. In: Complete Works - English translation. 1889: 12-291.

2. Koller W, Lang AE, Vetere-Overfield B, et al. Psychogenic tremors. Neurology 1989; 39: 1094-1099.

3. Fahn S, Williams PJ. Psychogenic dystonia. Adv Neurol 1988; 50: 431-455.

4. Monday K, Jankovic J. Psychogenic myoclonus. Neurology 1993; 43: 349-352.

5. Lang AE, Fahn S, Koller W. Psychogenic Parkinsonism. Arch Neurol 1994; in press.

6. Eldridge R, Riklan M, Cooper IS. The limited role of psychotherapy in torsion dystonia. Experience with 44 cases. JAMA 1969; 210 : 705-708.

7. Marsden CD, Harrison MJG. Idiopathic torsion dystonia. Brain 1974; 97: 793-810.

8. Cooper IS, Cullinan T, Riklan M. The natural history of dystonia. Adv Neurol 1976; 14: 156-169.

9. Lesser RP, Fahn S. Dystonia: a disorder often misdiagnosed as a conversion reaction. Am J Psychiatr 1978; 153: 349-452.

10. Weiner WJ, Lang AE. Movement Disorders: A Comprehensive Survey. Mount Kisco, NY: Future Publishing, 1989: 347-418.

11. Jayne D, Lees AJ, Stern GM. Remission in spasmodic torticollis. J Neurol Neurosurg Psychiatry 1984; 47: 1236-1237.

12. Friedman A, Fahn S. Spontaneous remissions in spasmodic torticollis. Neurology 1986; 36: 398-400.

13. Schwalbe W. Eine eigentumliche tonische Krampfform mit hysterischen Symptomen. Berlin: Inaug Diss, 1908:

14. Fahn S, Williams D, Reches A, et al. Hysterical dystonia, a rare disorder. Report of five documented cases. Neurology 1983; 33 (Suppl 2): 161

15. Batshaw ML, Wachtel RC, Deckel AW, et al. Munchausen's syndrome simulating torsion dystonia. $\mathrm{N}$ Engl J Med 1985; 312 : 1437-1439.

16. Williams DT, Ford B, Fahn S. Phenomenology and psychopathology related to psychogenic movement disorders. In: Weiner WJ, Lang AE, eds. Behavioural Neurology in Movement Disorders. New York: Raven Press, 1995: 231-257.

17. Ranawaya R, Riley D, Lang AE. Psychogenic dyskinesias in patients with organic movement disorders. Mov Disord 1990; 5 : 127-133.

18. Cooper IS. Involuntary Movement Disorders. New York: Hoeber, 1969:

19. Gowers WR. Diseases of the Nervous System. Philadelphia: Blakiston, 1888:

20. Rothwell JC, Obeso JA, Day BL, Marsden CD. Pathophysiology of dystonias. In: Desmedt JE, ed. Motor Control Mechanisms in Health and Disease. New York: Raven Press, 1983: 851-863.

21. Weiner WJ, Lang AE. Movement Disorders - A Comprehensive Survey. New York: Futura Publishing, 1989: 1-22.

22. Fletcher NA, Harding AE, Marsden CD. A case-control study of idiopathic torsion dystonia. Mov Disord 1991; 6: 304-309.

23. Jankovic J, Van Der Linden C. Dystonia and tremor induced by peripheral trauma: predisposing factors. J Neurol Neurosurg Psychiatry 1988; 51: 1512-1519.

24. Marsden CD, Obeso JA, Traub MM, et al. Muscle spasms associated with Sudeck's atrophy after injury. Br Med J 1984; 288: 173. 176.

25. Koller WC, Wong GF, Lang A. Posttraumatic movement disorders: a review. Mov Disord 1989; 4: 20-36.

26. Schwartzman RJ, Kerrigan J. The movement disorder of reflex sympathetic dystrophy. Neurology 1990; 40: 57-61.

27. Bhatia KP, Bhatt $M H$, Marsden CD. The causalgia-dystonia syndrome. Brain 1993; 116: 843-851. 
28. Schott JD. Induction of involuntary movements by peripheral trauma: an analogy with causalga. Lancet 1986; $2: 712-715$.

29. Calne DB, Lang AE. Secondary dystonia. Adv Neurol 1988; 50 (Dystonia 2): 9-33.

30. Dobyns WB, Ozelius LJ, Kramer PL, et al. Rapid-onset dystoniaparkinsonism. Neurology 1993; 43: 2596-2602.

31. Lang A, Fahn S. Movement disorder of RSD - letter. Neurology 1990; 40: 1476-1477.
32. Schwartzman RJ. Movement disorder of RSD - letter. Neurology 1990; 40: 1477-1478.

33. Nakashima K, Rothwell JC, Day BL, et al. Reciprocal inhibition between forearm muscles in patients with Writer's Cramp and other occupational cramps, symptomatic hemidystonia and hemiparesis due to stroke. Brain 1989; 112: 681-697.

34. Panizza ME, Hallett M, Nilsson J. Reciprocal inhibition in patients with hand cramps. Neurology 1989; 39: 85-89. 